\title{
A ADOLESCÊNCIA E O LIMITE
}

\author{
Josfâm Antunes de Macêdo \\ Psicólogo IFRN, Especialista em Psicanálise \\ josfam@cefetrn.br \\ Emanuelle Cortez de Souza \\ Psicóloga IFRN, Especialista em Psicopedagogia \\ emanuelle@cefetrn.br
}

\section{RESUMO}

O Instituto Federal de Educação, Ciência e Tecnologia do Rio Grande do Norte - Campus Natal Central tem como clientela alunos de cursos técnicos integrados, cursos técnicos subseqüentes, cursos superiores e cursos de pós-graduação. Para efeito deste artigo será trabalhada a clientela adolescente, ou seja, os alunos dos cursos técnicos integrados. Os psicólogos escolares desta instituição trazem neste trabalho reflexões sobre a adolescência e o limite a partir dos registros das atividades que desenvolvem nesta instituição escolar. Ações integradas com profissionais das mais diversas áreas desta escola, como também o próprio trabalho destes psicólogos diretamente com os alunos adolescentes, servem de subsídio para se pensar sobre a relação da adolescência com o limite, sendo esta uma temática bastante complexa, pois ela está relacionada diretamente com o imprevisível, que é a sala de aula e todo o seu ambiente complementar. Através destas reflexões deseja-se trazer contribuições para o polêmico campo desta relação e assim colaborar para o amadurecimento de todos envolvidos na cena de uma instituição de ensino.

PALAVRAS-CHAVE: adolescência, limite, escola

\section{THE ADOLESCENCE AND THE LIMIT}

\begin{abstract}
The Federal Institute of Education, Science and Technology of Rio Grande do Norte Natal Central Campus has the following customers: students of the integrated technical courses, of the subsequent technical courses, of higher education, and of the graduate studies. In order to accomplish the purpose of this paper, we will be working with adolescent customers, which are the students of the integrated technical courses. The school psychologists of this institution bring, into this study, reflections about adolescence and limits, taking into account the records of the activities that are developed in this school. Integrated activities with professionals from various areas of this school, as well as the work that the psychologists develop directly with teenager students, provide basic information that brings reflecting about the relationship of adolescence with limits, which is a very complex issue because it is directly related with the unpredictable, which is the classroom and all of their complementary environment. Through these reflections we wish to bring contributions to the controversial field of this relationship and, therefore, contribute to the maturation of everyone involved in the scenery of an educational institution.
\end{abstract}

KEY-WORDS: adolescence, limit, school 


\section{A ADOLESCÊNCIA E O LIMITE}

\section{INTRODUÇÃO}

Neste trabalho abordaremos o conceito de adolescência e de limite para depois fazermos articulações entre ambos usando como apoio a realidade profissional vivenciada pelos psicólogos autores, no Instituto Federal de Educação, Ciência e Tecnologia do Rio Grande do Norte, Campus Natal Central.

A Psicologia Escolar do IFRN, Campus Natal Central, tem como uma de suas atividades o trabalho em sala de aula. Esta ação é feita tanto com as turmas dos primeiros anos dos Cursos Técnicos Integrados quanto com as turmas dos quartos anos dos mesmos cursos. Turmas estas que possuem como clientela estudantes adolescentes. Tanto nos primeiros anos quanto nos quartos anos o assunto adolescência sempre vem à tona através dos próprios estudantes. E eles possuem liberdade para opinarem e falarem da forma que melhor expresse sua opinião. Essa ida da Psicologia às turmas é sistemática e dá-se uma (01) vez ao ano. Lá tratamos de temáticas referentes à realidade dos alunos nas séries em questão.

É também intrínseco à Psicologia Escolar conversar com os profissionais da comunidade do IFRN. Aproveitamos alguns destes comentários para ilustrar nossas reflexões.

O texto que agora apresentamos traz os pensamentos dos psicólogos escolares tanto sobre o trabalho com os alunos em sala de aula quanto sobre as conversas que tivemos com os profissionais da comunidade do IFRN.

As considerações que aqui trazemos referem-se ao trabalho executado pelos psicólogos Emanuelle Cortez de Souza e Josfâm Antunes de Macêdo no ano de 2008, no então Centro Federal de Educação Tecnológica do Rio Grande do Norte. No presente texto optamos por usar o nome atual desta instituição de ensino: Instituto Federal de Educação, Ciência e Tecnologia do Rio Grande do Norte, ou simplesmente IFRN.

Para melhor nos aproximarmos da realidade destas experiências conservaremos a exata frase dita pelos estudantes, ou pelos profissionais, aos psicólogos escolares no exercício da sua função no IFRN em 2008. São frases registradas em nossas anotações.

Optamos por trazer o tema adolescência e limite para discussão aqui neste espaço, já que são temas recorrente nas conversas dentro da comunidade profissional do IFRN. Consideramos que lançarmos essas nossas reflexões podem ajudar aos profissionais do IFRN, e também de fora desta instituição, a melhor elaborarem as tensões referentes à temática do limite frente a um aluno adolescente, e assim todos nós podermos criar alternativas de melhor lidar com esta tensão.

\section{REFLETINDO SOBRE A ADOLESCÊNCIA E O LIMITE}

O emocional está presente no desenvolvimento escolar do aluno. E é sobre isto que neste trabalho pretende-se abordar. 
Para tratar da adolescência e do limite não queremos nos distanciar destes temas analisando-os como algo alheio. Queremos nos aproximar da temática, pois enquanto a analisamos, os adolescentes estão vivenciando este contexto. A Psicologia que trazemos é uma ciência que estuda o subjetivo, a emoção do ser humano, mas que não está desvinculada da realidade em que vivemos, e esta realidade é a adolescência dos alunos do Instituto Federal de Educação, Ciência e Tecnologia do Rio Grande do Norte (IFRN), onde trabalhamos, e que convivemos em nosso dia-a-dia. Realidade ilustrada por uma das atividades da Psicologia Escolar aqui na instituição, como é o caso do nosso trabalho nos primeiros anos dos Cursos Técnicos Integrados nos quais conversamos com os alunos sobre o tema adolescência. Perguntamos aos alunos que temas eles gostariam de conversar. Um deles responde: "qualquer coisa que não seja Psicologia barata para jovens, outro acrescenta algo que não seja repetitivo e clichê". Assim, vemos que os nossos alunos também não desejam tratar de assuntos que lhes sejam alheios, distantes, mas sim querem tratar de assuntos que os toquem, os mobilizem porque diz respeito ao que eles vivenciam. Esta é a nossa intenção: trazer para os leitores deste artigo algo que fale do nosso dia-dia, de nossas inquietações, de nossas conquistas e dificuldades com a adolescência do IFRN. Queremos dar a este momento um toque de vida e emoção, o que muitas vezes nos falta.

Mas o que é adolescência? Ao ser indagado sobre o que seria a adolescência, um aluno relatou que: "a adolescência é uma etapa da vida, só isso, nada mais. Não existem tantas complicações nesta fase, são as pessoas exageradas que inventam”. Em relação ao mesmo tema, comenta uma aluna: “a adolescência parece algo louco, porém é normal."

Vamos começar transgredindo um limite. Qual? O limite socialmente aceito de que as faixas etárias são exatas e com características precisas e com comportamentos previamente esperados. Pois cremos que a infância, a adolescência, o adulto e o idoso não possuem idades com limites exatos nem muito menos possuem características psicológicas precisas e com comportamentos previamente esperados. Cremos que nós inventamos estes perfis, mas na realidade eles não são reais. Entretanto, paradoxalmente, para sermos didáticos e podermos ser entendidos, ao mesmo tempo trabalharemos com as faixas etárias socialmente aceitas: infância, adolescência, adulto e idoso, mesmo que questionemos a exatidão de todas as suas características. Aproveitando, já diríamos que este escrito traz em seu bojo uma série de paradoxos, que mais do que contradições intrínsecas a ele, são revelações da condição humana, revelações da complexidade que, ao nosso entender, é o viver.

No caminho de buscar uma definição para a adolescência afirma-se que ela é uma fase não natural do desenvolvimento (BOCK, 2002). Ela ocorre em algumas culturas e em outras não, varia de acordo com a classe social. Há sociedades em que a criança torna-se adulta em menos tempo. Na nossa, ela é derivada da estrutura sócio-econômica que exige um longo tempo de preparação para entrar na vida adulta, no mercado de trabalho, na formação de uma família, na independência dos pais, passando o próprio indivíduo a cuidar de si. Para Coll, Marchesi, Palácios (2004), durante séculos até o fim do século XIX as crianças se incorporavam ao mundo do trabalho entre os sete anos e o início da puberdade. Não existia uma cultura adolescente, nem a adolescência era percebida como um estágio particular do desenvolvimento. Tais autores explicam que com a industrialização houve a necessidade de formação e os estudos ganharam importância. Dessa forma, o grupo dentro dessa faixa etária considerada adolescente passou, em nossa sociedade, a ter características próprias. 
Hoje, em nosso meio, encontramos alguns tipos de adolescência. Esse período, mesmo dentro de nossa sociedade, não é igual para todos os jovens. Por exemplo, o jovem de 16 anos, que já é pai ou mãe, já trabalha para se sustentar ou sustentar uma família. Em outro exemplo, encontramos jovens de 20, 25 anos, ou mais, ainda dependentes financeiramente dos pais, preparando-se incessantemente para o mercado de trabalho, havendo, neste caso, uma prorrogação de sua independência. Pode-se perceber como o critério para delimitar a adolescência é flexível. Para Bock (2002, p. 291) "não temos adolescência, mas sim adolescentes”. Observa-se então que essa fase de desenvolvimento em nossa cultura é psicossocial, ligada aos valores sócio-econômicos.

Quando falamos sobre a adolescência somos levados a pensar em rebeldia, em transgressão. E essa transgressão, muitas vezes temida e difícil de ser lidada, é positiva e necessária ao jovem. Para muitos, enfrentar, desafiar, provocar, é a maneira de alcançar uma autonomia saudável. Às vezes, de tão preocupados com os alunos mais contestadores e polêmicos, não nos preocupamos com aqueles adolescentes mais resignados, calados, passivos, que tudo aceitam e nada questionam. Mas que adulto ele será? Cremos até que o tipo de metodologia usada pelo IFRN em sua formação cidadã, através do incentivo de muitos professores para que os alunos possuam uma concepção crítica da vida, através de seminários em que os alunos possam estudar e falar suas idéias, gera certa inquietação com o aluno demasiadamente passivo. Esse tipo de prática é considerada positiva, pois assim ensinamos ao nosso aluno que quem é o responsável por ele, em última instância, é ele próprio, daí nunca ser bem vinda uma passividade em demasia.

Este adolescente, tão socialmente ligado pela mídia à rebeldia e transgressão, é também por ela endeusado (CALLIGARIS, 2000). Basta ver que o nosso modelo de beleza é o modelo de um (a) adolescente. Os comportamentos de alegria se espelham no comportamento adolescente. A moda é inspirada na moda adolescente. O organismo saudável é o organismo adolescente. Grande parte dos modelos publicitários são adolescentes. Mas este adolescente tão socialmente endeusado pela mídia é também por ela demonizado (CALLIGARIS, 2000). Nesta vertente, tudo que ocorre de ruim hoje teria como culpado o adolescente: roubo, droga, batida de carro, gravidez indesejada, promiscuidade sexual, entre outras questões. Coisas que, em realidade, ocorrem em todas as faixas etárias. Só que tanto a cultura de endeusar a adolescência em sua aparência ou demonizar a adolescência em sua essência nos influenciam deturpando a nossa crítica sobre a pessoa com quem trabalhamos, impedindo que tomemos uma distância para ver melhor o sujeito adolescente. E tanto o adolescente aproveita o endeusamento que é feito dele quanto ele sofre com a crítica negativa injustamente feita a ele. Esta censura do adolescente feita pela mídia é muito pesada. É como se a sociedade criminalizasse os adolescentes para poder dizer: "eu não sou como eles". Porém, repetem atitudes semelhantes as que são criticadas. Dizem alguns adultos: "o adolescente só quer comprar futilidades”. Então, este mesmo adulto compra o carro que não pode, se endivida, quando poderia comprar um carro mais simples, que menos o endividasse, e não considera que dessa forma está comprando futilidades. Pois a atitude A ou B não caracteriza uma faixa etária, mas sim uma pessoa, já que todos somos humanos, e nossas maneiras de agir são muito similares independente da idade.

De fato, muitas vezes agimos fazendo o que criticamos nos adolescentes: em nossas reuniões saímos antes do fim; fazemos conversas paralelas em momentos inadequados; somos rebeldes em nossas atitudes cotidianas; talvez atendamos ao celular quando ele toca em um momento indevido, entre outras atitudes. Pois, apesar de adultos, somos muito 
parecidos com os adolescentes. Não há criança, adolescente, adulto ou idoso que seja santinho ou demônio. Logo, não existe nem aborrescente nem aborradulto.

Cremos que é necessário descriminalizar os adolescentes, acabar com os preconceitos a eles dirigidos, ver que os comportamentos deles estão em nós e os nossos estão neles. Até porque, enquanto faixa etária, um dia já fomos adolescentes. Disso não podemos esquecer. Ao contrário, pensamos ser melhor lembrarmo-nos das nossas qualidades e defeitos em nossa adolescência, lembrarmos de nossas faltas e presenças em nossa adolescência, para assim melhor compreendermos e lidarmos com o adolescente hoje.

Em essência, acreditamos, funcionamos tal e qual nossos alunos adolescentes ou como crianças ou como idosos. A civilização ocidental se organiza de maneira que define o adulto como o rei, é ele que sabe como as coisas são. Por isso, o adulto é melhor que a criança, o adolescente e o idoso. o adulto está sempre correto e sabe como as outras faixas etárias devem agir. Todas as outras faixas etárias devem estar submissas ao adulto. Mas será que é assim mesmo? Ou será que o limite etário é um mito a qual nos submetemos na tentativa de negar que o limite de cada um é único, não se repete, e segue de acordo com a maneira com que cada um efetua trocas com o seu entorno, e de acordo com a maneira que cada um recebe as influências do ambiente que o rodeia? É mais fácil pôr regras que delimitem precisamente cada faixa etária do que conviver com a incerteza de saber que cada um vai de acordo com um potencial infinito e por isso sem limite e sem precisão.

Se considerar a adolescência como um estado de surpresa frente a um novo que me toma e me deixa imaturo para saber o que fazer frente a algumas novidades, somos e seremos sempre adolescentes, pensamos, pois eternamente nos depararemos com um novo que nos deixará inseguros sem saber o que fazer. Se isto é ser adolescentes, então por todo o tempo seremos uns.

E o que é o limite? Se o limite for um enquadre previamente estabelecido onde todos a ele se submetam, podemos dizer que ele é a própria civilização. Mas o que diferiria a espécie humana das espécies de outros animais? Enquanto o limite de outras espécies, como por exemplo, dos leões, é rígido e inflexível, o limite da espécie humana é flexível. Nossas leis mudam com o tempo, a ciência quebra valores antigos, a democracia permite o rodízio de nossos dirigentes, entre outras alterações. Apesar da flexibilidade do limite na espécie humana isto não quer dizer que sejamos seres sem limites. Ao contrário, o temos, e bastantes. Tanto é que a nossa espécie tem se mostrado muito bem sucedida frente a outras espécies animais. Desta forma, vamos avançando no aprimoramento de nossa civilização por tentativa e erro, duvidando da certeza e do absolutismo, já que limitar não é fácil. De fato, o que caracteriza a nossa espécie é o diálogo entre a transgressão e o limite. Que o diga a própria ciência com seus avanços.

Para se processar esta nossa interlocução agora quantos limites estão em jogo? Inúmeros! Neste instante está a funcionar certo ritual que permite escrevermos e vocês lendo-nos. Isto é limite. Este texto está submetido a uma série de configurações, e a configuração é um limite socialmente aceito. Para ler este escrito de uma forma crítica você não pode lê-lo de qualquer maneira, pois uma leitura mais analítica requer certo ritual, e isto é um limite.

Colocar limites é algo subjetivo, cada um de nós tem a sua maneira particular de colocar limites. Não há receita. Tanto é muito subjetiva a forma de colocar as regras para alguém 
quanto reconhecer o que é ou não uma infração das mesmas. Que o diga o Poder Judiciário de qualquer país do mundo.

Buscando definir para si o conceito de limite é muito comum ouvir alunos falarem que liberdade é diferente de libertinagem. Eles se preocupam com o limite. Muitas vezes eles pedem limite. Para Serrão (1999), na busca de sua identidade, o adolescente contesta, critica, questiona e perde os limites, exigindo, simultaneamente, o restabelecimento desses mesmos limites. Quando em sala de aula, por exemplo, o professor diz que todos deverão entregar um trabalho na sexta-feira, e um aluno diz provocativo "professor, e se eu entregar na segunda?", este estudante pode estar talvez dizendo "olha, eu tenho vontade de infringir essa regra, mas diga-me o que fazer, dê-me a regra." Nós também pedimos limite. Imagine se todos pudessem atravessar um sinal de trânsito ao mesmo tempo? Imagine se todos fizessem o que desejassem? O limite barra o meu desejo para dar espaço ao outro. O limite mexe com o desejo que mexe com a transgressão.

A transgressão do aluno perante um professor pode não estar dirigida à pessoa do professor, mas estar ligada a uma necessidade de discordar ou de aparecer para se autoafirmar diante do grupo ou de si mesmo. Mas, independente do que levou aquele aluno a transgredir: o que fazer? Um professor não é máquina ou robô que já possui respostas padronizadas a todas as demandas. Porém, mesmo reconhecendo as limitações, fragilidades e impaciência dos professores, tomar uma atitude com aquele aluno representa se colocar contrário ao desrespeito à regra social que está sendo quebrada.

Muitas vezes, não é fácil para o professor pôr um limite no aluno. Há um vínculo entre o professor e o aluno que o professor quer preservar. Este vínculo é diferente do vínculo pai e filho, de amigo. $\mathrm{O}$ aluno, de fato, apesar de algumas vezes confundir, quer um professor que saiba reconhecer tanto o alcance quanto o limite da sua ação, numa dialética de dar de si, realizar algo, receber, trocar, ensinar e aprender. Nisso as mudanças se processam, acontecem as transformações. Quando o educador aceita os seus limites possibilita também ao adolescente aceitar os seus. Um cômico aluno diz: "o professor tinha o dom de fazer todos alunos dormirem”. Ao olhar deste aluno, nesta cena, dormir na aula deste professor não é uma transgressão, mas uma obrigação: ele acompanha o limite dado pelo professor.

O trote, cremos, é uma demonstração de ausência de limites por todos os lados. Alunos são constrangidos e agredidos como se fosse brincadeira no momento que estão chegando na instituição escolar e deveriam ser acolhidos e bem recebidos. Todos assistem ao trote e pouco é feito para evitá-lo enquanto agressão e constrangimento. Há uma silenciosa nossa cumplicidade também nossa. A agressão do trote é uma agressão gratuita e desnecessária. Mas nem toda agressão dá-se assim.

Voltando agora a tratar do nosso aluno adolescente, temos a hipótese de que muitas vezes a agressividade do adolescente (e a nossa também) é, em certo sentido, positiva, pois é ela que nos encoraja, é ela a nossa garra para enfrentar os desafios do viver. Winnicott escreve: "A principal idéia que este estudo da agressão veicula é que, se a sociedade está em perigo, a principal razão disso não se encontra na agressividade do homem, mas na repressão da agressividade pessoal nos indivíduos." (WINNICOTT, 1982, p. 355) Mas, algumas vezes, essa agressividade ultrapassa o meu limite ou o limite do grupo ou o limite do socialmente aceito. É aí que entra o não. Neste momento, podemos aproveitar e questionar: será que o adolescente precisa de mais limite do que um adulto ou de que uma criança ou de que um idoso? Por que o limite é sempre muito enfatizado diante da 
adolescência? E nós? Quando reagimos com agressividade diante de um limite imposto? Penso que esses questionamentos podem nos ajudar a sentir o que pode passar um adolescente que a tudo desafia e recebe limites a todo instante. Isto faz lembrar a pergunta de um aluno: "até que ponto devemos obedecer aos nossos pais?" Há limites para isto?

Apesar da existência dessa agressividade em certo sentido saudável, devemos ter cuidado com o psicologismo para explicar todo fenômeno de agressão. Por vezes se diz, em forma de chavão ou clichê, que todo comportamento do adolescente é devido à fase ou é por causa de frustrações e sofrimentos presentes e passados. Esse tipo de pensamento pode justificar-se, pois por trás de cada comportamento, manifestação de atitude nossa, há uma história, um ser em particular. Mas isso não deve restringir a necessidade do limite, do não. Até acreditamos que é possível, em algumas ocasiões, o aluno estar pedindo um limite, um não ao professor. O psicologismo, isto é, dar explicações psicológicas a tudo e acomodarse ao fato, não é educativo. Da mesma forma, controles ditatoriais e aceitação ingênua para a violência provocada pelo outro não são educativos. Precisamos do limite e sem ele não sobreviveríamos.

Mas teorizar é muito fácil, entretanto estar na prática diante de uma possível ou real transgressão, em uma sala de aula, perante um grupo de estudantes, e ter que rapidamente resolver o que fazer, é bem diferente de tudo que aqui escrevemos. É difícil, pois mexe com a emoção do professor e dos alunos. Existem as formas de transgressão já bastante conhecidas que com elas sabemos lidar muito bem: o aluno que não pára de conversar, o aluno que faz barulho na hora da aula, o aluno que fica soltando piadinhas agressivas insistentemente, o aluno que faz de tudo para chamar a atenção do professor e da turma, entre outros exemplos de transgressão. Muitas vezes, a provocação é sutil ou aparentemente ingênua ou disfarçada, mas nem por isso menos agressiva. Ou ainda, em algumas situações, não sabemos o que fazer, pois não temos claro se estamos diante de uma provocação ou não. Estes não são momentos fáceis para o professor. A seguir, alguns exemplos podem ser ilustrados.

Em uma prova de uma Disciplina Técnica a aluna cisma com um erro de Gramática que pouco alteraria o teor da pergunta e da resposta. Ela insiste nisto, quer uma solução e diz ser um absurdo no IFRN fazer uma prova com um erro gramatical daquele. A turma passa a apoiá-la. O professor reconhece o erro e explica que não vê maiores problemas em continuarem a fazer a prova. A aluna que reclama é tida como uma boa aluna, com liderança perante os colegas. E o professor sabe que a turma havia pedido muito para adiar aquela prova. Assim, enquanto o professor busca mostrar para a turma que aquele erro não impede em nada continuarem a fazer a prova, ele percebe que no tumulto gerado os alunos aproveitam para colar. O que fazer?

Em outra situação, a professora combina, como em todas as suas aulas, para os estudantes desligarem o celular. Logo após, o aluno mais calmo da sala chama-a e a professora vai até ele. Perante a professora ele lê uma mensagem em seu celular enviada pelo aluno que tem as melhores notas da turma. $\mathrm{O}$ aluno ausente justifica para a professora porque faltou. A professora indaga ao aluno dono do celular: "nós tínhamos combinado para desligarem o celular, por que não desligou?" O aluno que a chamou na carteira responde: "Eu desliguei, deixei o celular no 'silencioso'.” Neste exemplo entram em questão várias coisas. 1) Desligar um celular é colocá-lo no 'silencioso'? 2) O aluno que a chamou fez isto por uma decisão sua ou foi pressionado pelo colega que enviou a mensagem? 3) Esta pequena transgressão a professora deve relevar ou levar em conta? 4) O aluno que enviou a 
mensagem e que sabe que toda a aula a professora combina para os celulares serem desligados, foi ingênuo ou tem por trás de sua atitude uma busca de burlar o limite colocado pela professora? O que fazer?

Em outro exemplo, um professor sempre dá aula de porta aberta, e assim também realiza suas provas. Mas passa a considerar que não está sendo bom fazer as provas com a porta aberta, pois os alunos ficam olhando para a porta, para o lado de fora. Resolve que fechará a porta no dia da prova, anuncia para a turma e vai fechando a porta. Quando o faz, um aluno pede para deixá-la aberta pois é claustrofóbico. Trata-se do aluno que mais reagiu não querendo a prova naquele dia. O que fazer?

Em mais uma situação, uma professora conversava com uma turma sobre a flexibilidade do corpo: questões da idade, corpo mais rígido e menos rígido, acrobacias, entre outros assuntos relacionados. Aquele assunto empolgou a turma. Então, um aluno de 14 anos, bastante pacato, se levanta, vai até a frente, e próximo à professora dá uma cambalhota no chão, sorri e diz que ele tem uma flexibilidade boa. A turma bate palma e continua a conversar como se nada tivesse ocorrido. A professora perplexa fica sem saber o que fazer. O que fazer?

Em outra turma, um professor passa a desconfiar que o melhor aluno da turma, que é também o líder da sala com grande influência sobre os colegas, está em franca competição com ele. Este aluno faz tudo da maneira mais elegante possível, sempre buscando desautorizar o professor perante toda a sala. O melhor aluno da sala, ou o líder da turma, faz isto de maneira tão discreta que fica difícil para o professor dar um não ou escancarar que há uma agressão naquela aparentemente ingênua atitude daquele aluno. O que fazer?

Qual o limite do professor? Até que ponto um professor pode ou deve suportar um aluno? Não há resposta para isto. Depende de cada um. Depende de cada professor, de cada aluno, de cada turma, de cada dia, de cada hora, de cada instante. Poderia se dizer: "o professor suporta mais o aluno com quem ele tem mais amizade". Ou poderia se dizer o contrário: "o professor suporta menos o aluno com quem ele tem mais amizade.” Há uma regra? Não! Há um arco-íris de flexibilidades possíveis na subjetividade deste campo.

Alunos adoram acusar colegas filhos de servidores do IFRN como sendo recebedores de privilégios. Dizem alguns: "professor, aquele aluno é filho de um servidor daqui, ele tem amizade com todos professores, por isso ele tira notas boas.” Porém, até agora, nada nos comprova esta insistente denúncia. O problema está nos alunos que inventam esta acusação, ao nosso ver, infundada. Aqui nada nos diz que este limite esteja sendo pervertido.

Com exemplos simples como esses, sem maiores agressões, percebe-se que aqui no IFRN poucos são os casos de violência explícita. Em outras escolas existem desrespeitos aos professores bem mais intensos do que aqui. Por quê? Porque aqui a agressão é geralmente escutada antes que ela tome maiores proporções, antes que ela se transforme numa ação violenta. Temos o hábito de estarmos sempre de portas abertas para escutar os alunos e suas queixas. Mérito dos professores do IFRN e de sua equipe técnica. No sentido inverso, quando não se reconhece a agressividade do outro, não se reconhece a própria agressividade, então tudo vira uma atuação agressiva e as coisas perdem o controle, podendo virar um círculo vicioso. 
No nosso entender, aqui, nesta instituição escolar se conseguiu dar à palavra o status que ela merece. Se há palavra, o risco do desejo de transgredir para destruir, virar ação, tornase mínimo. O silêncio, a censura corrói, agride, vira guerra. A palavra sempre é uma busca de caminhos civilizatórios, mas há momentos em que a palavra esgota. O que fazer? Um paciente professor explica várias vezes que ali não dá para o aluno conversar. O aluno insiste em conversar. Por que o professor não pode convidar o aluno para retirar-se da sala? Há algum erro em um professor retirar o aluno da sala? Ainda mais quando este professor buscou repetidamente a palavra para sensibilizar o aluno que ali não era a hora dele conversar, para sensibilizar o aluno da atenção necessária aquele momento, onde o professor quis garantir a direito dos outros alunos escutarem atentamente a aula. Ao nosso entender, não há qualquer problema em retirar o aluno da sala. Esta poderia ser a melhor ação que o professor tinha de fazer. Ou era isto que aquele aluno pedia. Em um outro momento, o professor pode até procurar aquele aluno para conversar e saber o que está havendo. Mas provavelmente naquela hora não havia nada mais a fazer do que convidar o aluno para retirar-se. Há alguma regra de como um professor deve agir? Não há. Voltamos ao que antes dissemos: isto depende de cada um.

Se nos indagarmos: quanto o IFRN ajuda aos alunos a viverem a sua adolescência, sua vida? Consideramos o quanto é rico o estar do aluno aqui no IFRN, pois podemos encontrar uma variedade de realidades sócio-econômicas e afetivas. Quem mais se beneficia com isso são nossos alunos, pois podem se deparar com uma adolescência diferente da sua e crescerem com isso. É comum ouvirmos depoimentos dos alunos do quarto ano, com quem trabalhamos em sala, do tipo "eu não me arrependo de ter entrado no IFRN. Hoje sou outra pessoa, ou vejo o quanto amadureci no IFRN. Eu conheci muita gente diferente de mim e tive que aprender a me relacionar com elas." Percebemos nestes depoimentos uma caminhada que fala de contradições, de atropelos, de idas e vindas, mas um percurso que é realizado a cada dia em nossa instituição. Por trás disso, está a colaboração de cada um de nós, que foi instrumento para esse crescimento dos alunos em todos os aspectos de suas vidas.

O IFRN, acreditamos, trabalha com os seus alunos de uma maneira bastante acolhedora. Ao mesmo tempo em que protegemos o aluno também lhe damos incentivo em sua autonomia, responsabilizando-o por seus atos, valorizando seu exercício de entrada na vida adulta.

Explicitando mais um exemplo: uma turma vários alunos foram suspensos pela instituição devido a uma transgressão que aquele grupo claramente cometeu. Associado a isto o IFRN, também exigiu deles o trabalho comunitário em uma instituição de caridade. Os alunos, dias depois, comentavam: "professor o trabalho lá (na instituição de caridade) valeu de nada. Se eles (os Diretores do IFRN) pensavam que a gente ia achar ruim a gente achou foi bom, a gente ficou foi com saudade do povo de lá. E ajudar até que é bom." O não reconhecimento dos alunos do trabalho comunitário exigido pelo IFRN nada mais traz embutido do que o reconhecimento de quanto aquela ação foi educativa e acertada: "ajudar até que é bom." Se aqui eles transgrediram, agredindo ao outro, no trabalho comunitário aprenderam que "ajudar até que é bom."

Cremos que mais importante do que definir precisamente o que é o limite e o que é a adolescência é poder realçar a importância da palavra e do limite para o convívio cidadão entre todos nós. A esperança, pensamos, está na palavra e no limite. Algo que acreditamos ser de difícil acordo. Não é fácil o acordo entre a palavra e o limite, até porque segue 
conforme cada um. Cada um é singular, original, não se repete, pois não há ninguém igual a ninguém. Pensamos que esta instituição, o IFRN-Campus Natal Central, possui suas dificuldades - e não daria para ser diferente, a não ser que acreditássemos na ilusão da perfeição - mas vem sabendo bem fazer um acordo entre a palavra e o limite. Dito de outra maneira, apesar de nossas grandes dificuldades e facilidades para aqui trabalharmos e exercermos nossos ofícios, nós conseguimos um acordo entre a palavra e o limite. Aí está uma originalidade do IFRN. Quem já trabalhou em outros colégios sabe muito bem disto que falamos. Aqui, sem dúvida, nós nunca ficamos quietos, sempre estamos insatisfeitos buscando cada vez mais acertar, o que é ótimo, fantástico. Prova é este texto poder circular na revista científica do IFRN (a HOLOS) tratando da adolescência e o limite.

Na cultura do IFRN, de valorização da formação cidadã, terminamos por incentivar o nosso aluno para a transgressão no sentido de uma transposição social, ajudando-o a canalizar sua agressividade para a luta por vencer as barreiras sociais e tornar-se um sujeito participativo, para que a sua ação seja capaz de interferir no curso da sociedade.

Pelo que falamos deve ter dado para perceber que não somos dos que compartilham com a idéia de que tudo está piorando, de que tudo está perdido. Acreditamos que se temos perdas ao longo da nossa história também temos ganhos, talvez até maiores do que as perdas que temos enfrentado em nossas vidas dentro e fora do IFRN. Por exemplo, hoje vivemos bem mais tempo do que antes. Isso é bom, pois todos queremos viver e ser felizes.

\section{CONSIDERAÇÕES FINAIS}

Aqui foram expostas reflexões sobre a adolescência e o limite. Este estudo nos permitiu concluir que fácil é definir o conceito de adolescência e de limite. Entretanto o difícil está no que vai além do conceito de adolescência e no conceito de limite. Percebemos que o que se torna árduo é conviver com a minha adolescência, com o meu limite ou conviver com a adolescência do outro, o limite do outro.

Acreditamos que a dificuldade de lidar com o limite está exatamente na dúvida, e não na certeza. O limite mexe com o sim e o não, com a aceleração e o freio, o faço e o não faço, mexe com o desejo. O limite está ligado à própria surpresa, ao imprevisível. Não há um enquadre prévio. Alguém sabe, por exemplo, responder qual o limite da morte? È difícil responder, porque viver é difícil, é complexo, não há macetes nem há regras. Estamos sempre a caminhar numa linha que contempla tanto a continuidade quanto a mudança.

O que trazemos com estas palavras traduz um pouco das inquietações da nossa existência, da condição humana - loucura e liberdade ao lado de controle e responsabilidade. Vontade de ser criança, adolescente, adulto e idoso ao mesmo tempo. Percebamos o idoso que fala muito na infância, como se quisesse revivê-la sempre, como se quisesse transgredir a velhice na direção da infância que não volta mais.

Esta é a nossa visão sobre o tema em questão, mais em forma de dúvidas do que certezas, mais em forma de reflexões que crêem serem as coisas da vida relativas e não absolutas, mais em forma de pontos de vista do que de verdades.

\section{REFERÊNCIAS BIBLIOGRÁFICAS}


1. BOCK, A. M. B. Psicologias: uma introdução ao estudo de psicologia. São Paulo: Saraiva, 2002.

2. CALLIGARIS, C. A adolescência. São Paulo: Publifolha, 2000.

3. COLL, C. MARCHESI, A., PALACIOS, J. Desenvolvimento psicológico e educação. Porto Alegre: Artmed, 2004.

4. SERRÃO, M. Aprendendo a ser e a conviver. São Paulo: FTD, 1999.

5. WINNICOTT, D. W. Agressão e sua relação com o desenvolvimento emocional. In: __ . Textos selecionados: da pediatria à psicanálise. Rio de Janeiro: Francisco Alves, 1982. p. 355-374. 